\title{
REVIEWS AND CRITICISM.
}

Youth: Its Education, Regimen, and Hygiene. By G. Stanley Hall, Ph.D., LL.D., President of Clark University and Professor of Psychology and Pedagogy. New York: D. Appleton \& Company, 1906. $\mathrm{x}+379 \mathrm{pp}$.

President Hall has rendered a great service to the many teachers interested in his work and opinions, by culling from the exhaustive treatise on "Adolescenee" the data and conclusions which he considers of the most practical pedagogical value. With the exception of the last chapter on moral and religious education, "Youth" is a repetition and rearrangement of certain parts of the larger work. The more technical portions are omitted, as well as much that is interesting chiefly from the poetic or emotional standpoint. Enough of the latter remains, however, for President Hall throughout the smaller as well as the larger work makes quite as strong an appeal to emotion and sentiment as to the scientific spirit.

Though President Hall has recognized the necessity for simplification in this popular edition of the two , volume treatise, he evidently could not quite bring himself to sacrifice all of his characteristic and sometimes unique verbiage on the altar of simplicity. He has, however, compromised by adding a glossary for the explanation of such terms as rabulist, chrestomathy, ephebic, eviration, paleopsychic, and temibility.

Hall's basic theory of education is that at every stage of a child's life the environment and instruction should be closely adapted to the degree of the child's mental and physical development. This ideal education can, of course, only be realized by a system founded upon a comprehensive biological and psychological understanding of the developing child. To attain this vantage point the author has collected a vast amount of data from every available source.

The biological standpoint is established in the first two chapters. The school life of a child is divided into two periods, the pre-adolescent, from eight years of age until twelve, and the adolescent from twelve upward. During the first stage health is at its best, weight, activity, vitality and endurance are increased, the brain has attained nearly its adult size, and perception is very acute, while reason, æsthetic enjoyment and love are still but slightly developed. The qualities first to appear are the inheritance from remote ancestors, while those developing during adolescence are neo-atavistic. The early, more or less savage instincts, should in Dr. Hall's opinion be given an opportunity to realize themselves. If they are suppressed at this, their natal season, they are apt to burst forth later in much more dangerous 
forms. Herein lies the danger of precocity, which should be warded off by methods similar to the Aristotelian methods of catharsis. If the environment forbids a natural method of satisfying these tendencies, the child should be told stories of primitive peoples and their customs, and encouraged to live as much as possible out of doors and among the trees, flowers and animals.

In the school room all appeal to interest and understanding should be postponed until after the age of twelve. In the years between eight and twelve the child is peculiarly plastic and susceptible to drill and discipline. "It is the age of external, mechanical training. Reading, writing, drawing, manual training, musical technic, foreign tongues and their pronunciation, the manipulation of numbers and of geometrical elements, and many kinds of skill have now their golden hour. . . Pedagogic art consists in breaking the child in to them betimes, as intensely and as quickly as possible with minimal strain, and with the least amount of explanation or coquetting for natural interest, and in calling medicine confectionery. . . . The automatic powers are now at their very apex, and they can do and bear more than our degenerate pedagogy knows or dreams of."

With the dawn of adolescence comes a complete change, both physical and mental. Rate of growth is greatly increased, while the growth of individual parts and organs is less uniform. On the psychic side the more distinctly human qualities are born and the time has come to make a direct appeal to the child's reason and emotion.

President Hall, however, is of the opinion that many of the qualities usually associated with puberty may develop earlier; that in this respect the order of development in the individual often departs from that of the race. Dr. C. Ward Crampton, in an article entitled "The Influence of Physiological Age upon Scholarship," which appeared in The Psychological Cuinic, Vol. I, No. 4, claims that psychological age should be substituted for age in years in all grading and classification of children between the ages of nine and seventeen years. If Dr. Hall's conclusion is correct, the physiological age would be no surer index of mental development than the chronological.

Great stress is laid upon the necessity for well-planned and welltimed muscle training, nearly one-third of the volume being devoted to this subject. The muscles of the body are grouped in two classesthe fundamental, which control the movements of the trunk, limbs, neck, etc., and the smaller accessory muscles which govern the movements of the hand, tongue, face, organs of articulation, etc. The fundamental muscles are earliest called into activity and should be much exercised during the pre-adolescent period. The accessory muscles might be called organs of thought, the thought playing upon them by changing their tension. They are small and may be combined in action in various ways. These muscles should be sparingly exer- 
cised in pre-adolescence and in early adolescence. If they are exercised too much or too early, nervous-muscular irritability will be the result. Such a state is perhaps the best physiological characterization of precocity. As the number of habitual movements increases, the necessity for inhibiting and organizing the movements arises. This is not accomplished without great effort; only gradually does the child gain control over the muscular powers which it has developed.

Methods of motor education are treated under four headings,industrial education, manual training, gymnastics, and plays, sports and games.

In industrial education diversity of training should be the aim. It should exercise all those muscular activities which, since their development through the early struggles of the race with the environment, have been the inherited tendency of mankind. Young people who till the soil, build, manufacture, etc., are repeating the history of the race and thereby laying the best foundation for intellectual careers. The middle and later "teens" is the age best adapted for this sort of training. The best industrial schools in the land, in Dr. Hall's opinion, are some of the institutions for negroes, Indians and juvenile delinquents.

The principle which underlies the manual training of to-day is "Keine Kentnisse ohne Fertigkeiten." Man excels the higher anthropoid apes almost as much in hand power as in mind, and as the manual areas of the brain are contiguous to the psychic zones, the development of manual dexterity is also potent in opening the intellect. The prevalent methods are at fault in laying too much stress upon the development of the smaller muscles, at the expense of those of the legs, back and trunk; also in concentrating too exclusively on technic, sacrificing content to form, and thus falling into the error which has always marked degeneration in education.

A good system would extract basic types of work from all the manual occupations in which men now engage. It would adapt these types to the nature and needs of the youthful body and will at each stage of its development. Each operation and each tool would be studied with reference to its orthopædic value, bilateral symmetry, the muscles it develops and the habits it forms. Finally, uniformity of method would give way in every instance to individual adaptation.

As yet there has been no effort to develop such a system. Sloyd claims to have accomplished it for woodwork; there has been, however, hardly an attempt to give either a physiological or psychological justification for a single step in the graduation or correlation of the sloyd exercises. Moreover, it is largely handwork and absolutely unadapted to the needs of early adolescence.

Gymnastics is treated from the historical standpoint. The four ideals which underlie the physical culture idea are discussed. These 
are, (1) The training of all possible bodily movements, (2) The development of voluntary control of all movements, (3) The training of those muscles which are seldom used, and the exercise of extensor muscles in order to produce a buoyant mental attitude, (4) The training of muscles for the purpose of attaining symmetry and correct proportions, the norms being the averages laid down by anthropometric tables.

The "need [of modern gymnastics] is radical revision and coördination of various cults and theories in the light of the latest psychophysiological science . . . The present academic zeal for physical development in in great need of closer affiliation with anthropometry." The ideal gymnasium should offer thorough courses in methods of taking anthropometric measurements, in anatomy, physiology, hygiene, and the history of gymnastics. President Hall also thinks it would be wise so to expand these courses that they could in large measure satisfy the requirements for the A. B. degree. Such a step would, he thinks, broaden the sphere of the college and would supply the growing demand for physical trainers.

Play is considered as an expression of those instincts inherited from remote ancestors, it is a re-enactment of race habits, not a preparation for future adult activities. This is why play is entered into with such zest and enjoyment. Gulick's idea is quoted, that those activities are most interesting which at some time in race history were necessary to survival, and it is shown that such activities, although no longer necessary from the point of view of utility, are necessary for the full development of the body, which has its present form only as the result of its racial evolution.

In games, as in all other muscle training, children must be led to exercise first the fundamental muscles and later the accessory. "Hereditary momenta really determine, too, the order in which nerve centers come into function. The oldest racial parts come first, and those which are higher and represent volition come much later." Hughlings Jackson is quoted as having pointed out how this is exemplified in the early development, by the acts of mastication and deglutition, of the muscles destined to be used later in speech. Perhaps it is the necessity of this preliminary muscular exercise for the normal development of the power of speech which partially accounts for the fact that many feeble-minded children, who have not passed beyond the bottle stage of feeding at the age of five, six, or even eight years, have failed to develop the faculty of speech; especially as it is also a fact, that after such children have been trained to eat solids, it is possible in many cases to teach them to talk.

Great stress is laid upon the educative power of rhythmic movements. It is suggested that rhythm may have been the great basic tendency from which play, art, and work all spring. Adolescence is the period of greatest susceptibility to rhythm, and dancing is extolled as 
the best of rhythmic exercises. When used aright dancing "can cadence the very soul, give nervous poise and control, bring harmony between basal and finer muscles, and also between feeling and intellect, body and mind. It can serve both as an awakener and a test of intelligence, predispose the heart against vice and turn the springs of character toward virtue."

The rhythm of work and relaxation among primitive peoples and adolescents is contrasted with that of the adult adapted to modern conditions. The dislike of regularity and continued work, so evident in youth, may be simply an expression of a phase of individual development corresponding to a more primitive era in race history.

The results of many interesting investigations on the subject of children's plays are presented.

Play itself is idealized. "All true play," says President Hall, "is love and prayer," and again, "play is, at bottom, growth, and at the top of the intellectual scale it is the eternal type of research from sheer love of truth."

The chapter on faults, lies and crimes consists largely of reports of investigations on these subjects. It is pointed out that educational advantages often increase crime among young people, introducing new and complex kinds, of which they were incapable when more ignorant. Youthful crime is an expression of educational failure, for the ultimate verdict concerning the utility of school will be determined by its moral efficiency in saving children from vice and crime. Ignorance is not incompatible with virtue, and President Hall condemns the idea that any merely educational training can moralize. How to deal with juvenile delinquents, he considers the great question of criminology, and he believes it should be made the basis of the study of ethics, which should work its way through this concrete beginning to a larger and higher philosophy of conduct than is commonly taught to-day.

Much information as to the nature of adolescents is gleaned from biographical and autobiographical studies of youth. The youthful characteristics of many well-known men are sketched, and autobiographies of a number of men and women are quoted freely. Such literature, President Hall thinks, should have a place of its own in the history of letters and criticism, and much of it should be used as reading matter for the young.

The gradual change in the character of the social ideals, as the child grows older, is shown by a presentation of the results of some thirty investigations, many of them made by the questionaire method, on the subjects of children's ideals, ambitions, ethics, property, judgment, crimes and social organizations. As children advance in age they tend more and more to choose their ideals from among public or historic personages, and to depend more largely upon ethical, artistic, 
intellectual or military qualities. Girls are very apt to choose men as ideads; this President Hall regrets, and advises that lives of great women be substituted for those of men in their courses of study. But why, when girls name men as ideals, is it necessary to believe that they wish to be men? It may mean only that they admire the particular virtues which those men possess. A girl who chooses Marcus Aurelius for her ideal may only mean that she values highest such moral qualities as he displayed.

In treating of intellectual education, Dr. Hall places first in importance the study of the vernacular language and literature.

Both high school and college students, he finds, have a very poor command of their native tongue. This fact he traces to four errors in educational method:-(1) Too much time is given to the acquisition of other languages at the period when attention should be focused on the native tongue. (2) There is an over-emphasis of grammar and form at the expense of literature, a subordination of content to form. "The great teacher who, when asked how he obtained such rare results in expression, answered, 'By carefully neglecting it and seeking utter absorption in subject-matter,' was also a good practical psychologist." (3) The neglect of oral language training, and the substitution of too much book-work and too many written exercises. (4) The neglect of training in abstract thought which is a consequence of the concrete teaching methods of the day.

Without the power of abstraction and generalization high mental development is impossible, and thought is of that elementary, halfanimal kind which consists of imagery and lacks even the elements of creative imagination. "It is as if what are sometimes called the associative fibres both ends of which are in the brain, were dwarfed in comparison with the afferent and efferent fibres that mediate sense and motion." The facts of aphasia are cited to prove "that the soul of language as an instrument of thought consists in this non-presentative element." In progressive aphasias, words designating objects and acts familiar to the patient are first lost, and only later those words used in abstract thinking. The reason of this President Hall thinks is obvious and states it as follows: "It is because concrete thinking has two forms, the word and the image, and the latter so tends to take the place of the former that it can be lost to both sense and articulation without great impairment, whereas conceptual thinking lacks imagery and depends on words alone, and hence these must persist because they have no alternate form which vicariates for them."

It is obviously necessary for coherence of thought that the words for abstractions be retained, but it is not quite so obvious why this necessity should determine the seat of the brain lesion, or if the modern theory of definitely circumscribed speech centers be abandoned, why a slight functional disturbance should necessarily wipe out concrete 
verbal thought rather than abstract. Abstract thought is a later development, the result of more complex processes, and therefore in a degenerative process it might be expected to be first effaced.

The failure of the schools to initiate students into the art of abstract thinking at a period when their development requires it, is well brought out in the returns of a number of questionaires on the subjects of children's slang, interest in words, stories, etc. These show that there is a natural tendency at adolescence toward abstract thought and that when appropriate words are not presented, any words are adopted which express concisely, accurately and forcibly the ideas and feelings which are dominant. Slang words have these qualities and in consequence they make a strong appeal between the ages of twelve and fifteen. During the same period is developed an intense enthusiasm for books, which increases steadily up to the age of sixteen, girls usually preferring books written by women, and boys those written by men.

The results of several interesting studies on children's memory, point to the conclusion that power of memory is correlated with age rather than with intelligence, increasing as the child grows older.

In closing the chapter President Hall urges the need of investigating the mentality of adolescents in almost all its phases, and expresses the opinion that school boards and teachers' associations should aid in making such investigations possible.

In discussing the education of girls Dr. Hall insists that just as educational methods must be adapted to the stages of the child's biological development, so must they be adapted to the characteristic differences of the sexes. He believes that co-education, especially in the high school, is apt to have a bad effect on both boys and girls. If the girls predominate, as they usually do in the high schools, the curriculum is likely to become feminized, which means that content and utility must give way to form and method; the boys become restless and drop out of school or they grow content with mechanical memorizing. Constant intercourse with girls also lessens the power of the latter to charm and interest. The effect on the girls is considered bad, in that it threatens her femininity by encouraging the adoption of masculine ideals, also in that familiar intercourse with boys of her own age at a time when her earlier maturity would make older men more congenial, tends to lower her opinion of men. It does not occur to Professor Hall that one of these evils might neutralize the other.

President Hall believes that woman has proved her intellect to be the equal of man's; he objects, however, to the conclusion that because woman can do many things as well as man she should do them.

He sketches in broad outline a plan for the education of girls. This he bases upon a conception of woman's nature, which though just in some respects, is tremendously exaggerated and even false in others. 
This conception is partly based on data contained in such autobiographical outpourings as those of Stella Klive, Mary MacLane, Hilma Strandberg, and Marie Bashkirtseff, whom he calls "veritable spies upon woman's nature; [who] have revealed the characterlessness normal to the prenubile period in which everything is kept tentative and plastic, and where life seems to have least unity, aim, or purpose."

Few people who are moved to write autobiographies are altogether normal, and those mentioned are surely not exceptional in this respect. I feel confident that to many commonplace women the first intimation of the existence of sentiments akin to those expressed by Mary MacLane was received through the pages of her book or those of President Hall.

'The plan for girls' education is in brief as follows: Its end and aim should be to prepare for motherhood. Perfect health should be the desideratum. There should therefore be plenty of exercise both in the open air and gymnasium and as little physical strain as possible. Stress should be laid upon manners and effort made to ineulcate a regard for the feelings of others. The purely mental should be held back to give opportunity for the deepening of the intuitions. Religion should be emphasized and its æsthetic side not neglected. Only the rudiments of mathematics and the sciences should be taught, and these concretely and out of doors when possible. The study of animal life should lead up to that of heredity, which should have a dominant place and be followed by studies of myths, customs, beliefs, domestic practices of savages, and animal traits in infancy and childhood, always with the chief emphasis on great results and basic principles. History should be taught largely through biography, and sociology should have a prominent place. Art should be presented with the aim of cultivating a discriminating taste. In literature, myth, poetry and the drama should lead, and Greek, Hebrew and Latin give place to German, French and Italian. Metaphysics, epistomology and logic should have a small place, genetic psychology should be taught and developed through the love of infancy and youth. Domesticity, child study, pedagogy and a course in maternity and nursing complete the curriculum. Finally, the methods throughout should be objective and concrete, book study.should be limited, examinations reduced to a minimum and "everything be as suggestive and germinal as possible. Hints that are not followed up, information not elaborated, seed that is sown on the waters with no thought of reaping . . . training which does not develop hypertrophied memory-pouches that carry, or creative powers that discover or producethese are lines on which such an institution should develop."

President Hall prophesies that if ever a woman Descartes does arise, her watchword will be not cogito, ergo sum, I think, therefore I am, but sum, ergo cogito, I am, therefore, I think. This is probably true, but it is also true that there are plenty of women to-day, not Descartes 
by any means, who already realize the force of sum ergo cogito, who, because they exist, must think, and for whom such a smattering of many things as is outlined above would be entirely unsatisfying and incomplete. In the chapter on intellectual education President Hall has pointed out that such concrete sensory training as he advises for girls, produces a mind incapable of any but infantile thought; in the chapter on moral and religious training he shows that, "only great concentration and prolonged efforts in one direction really train the mind, because only they train the will beneath it." "Only the sense of power and effort which made Lessing prefer the search to the possession of truth . . . counts for character." He therefore practically advises that woman be given an education which will necessarily make her a fine physical creature, dominated by emotion and sentiment, but childish and primitive in thought and without will or moral force.

In the final chapter on religious and moral training, it is shown how important it is to supplement all training by a conscious effort to develop the will. This may begin in the cradle by awakening the power of love, and continue throughout early childhood by a careful guidance in the formation of habits, and an effort to inspire sentiments of religious awe and reverence. If in intellectual fields the work be prolonged and thorough in one direction, and if this be supplemented by systematic muscle training, the youth will find himself at the dawn of manhood capable and self-controlled.

The great strength of the book is its pedagogical value, which is twofold,-(1) It points out unerringly and convincingly many weak points in the present educational system; (2) It gives precise and illuminating advice as to the direction and methods of research which will be of most value in overcoming these defects.

Its weakness is its incomplete, sentimental conception of woman and her educational needs, and the distinctly unscientific appeal to the emotional nature which is conspicuous throughout the book and decidedly detracts from its force.

C. H. T.

\section{NEWS AND COMMENT.}

Five years ago the Visiting Nurse Society of Philadelphia placed a nurse in a large public school in one of the poorest quarters of the city, to work in conjunction with the medical inspector. They chose Miss Anna L. Stanley for this post, and for several years she carried on the work alone. Last fall the society placed four other nurses in the schools, under the direction of Miss Stanley. As a result of the successful pioneer work done by the Visiting Nurse Society, Councils have recently authorized the Board of Education to appoint a super- 